\title{
Influence of architectural and planning solutions on fire risk in public buildings
}

\author{
DAuyezova Ulpan ${ }^{1}$, iD Alizhan Kazkeyev ${ }^{1, *}$ \\ ${ }^{1}$ Department of Structural Engineering, L.N. Gumilyov Eurasian National University, 2 Satpayev str., Nur-Sultan, \\ Kazakhstan \\ *Correspondence: alizhan7sk@gmail.com
}

\begin{abstract}
This article is devoted to the study of the influence of architectural and planning solutions on fire risk in public buildings. The calculation and assessment of fire risk was carried out on the example of one floor of a conditional office building with a free layout, where the tenant himself can change it at will. The input data for the calculation were two different layouts of the same floor, while the total square footage remained unchanged. As a calculation tool used the software package FireCat, which includes the programs Pyrosim, Pathfinder and FireRisk. The calculation took into account parameters such as the degree of fire resistance of the building, the number of rooms, the width and direction of door opening, the number of people on one floor of the building, including various mobility groups. Simulation modeling allowed to compare architectural and planning solutions for the same building and choose the best layout in terms of individual fire risk.
\end{abstract}

Keywords: fire safety, evacuation, architectural and planning solution, evacuation simulation, individual fire risk, FireCat.

\section{Introduction}

Nowadays, the rate of construction increases every year. For example, in spite of the COVID19 pandemic, in 2020 in Kazakhstan the construction of residential buildings was allocated 1968 billion tenge, which is 33\% more than in 2019 [1]. Such growth is caused by the increasing level of urbanization in the country, which inevitably entails the construction of buildings of higher storeys. In this regard, architectural and planning solutions in the construction of high-rise buildings become more complex, which makes the issue of fire safety relevant. One of the most important parameters, taken into account in the design of reliable and safe buildings, is the calculation of fire risk. According to the standard [2], fire risk - a quantitative characteristic of the possibility of realization of fire hazards and their consequences for people and property.

Timely evacuation from the building is one of the most important tasks for ensuring the safety of people in case of fire [3-6]. Preventing fire hazards in a building is accomplished by evaluating the individual fire risk, which is an indicator of the fire risk to human life. Individual fire risk (risk of death in a fire) is a quantitative characteristic of the possibility of death of an individual as a result of the effects of fire hazards [2-7]. Today there are many techniques to estimate this indicator, one of which is the use of specialized software that allows to quickly make the necessary calculations and provide a visual representation of the evacuation process [8-11].

As a rule, smoke and carbon monoxide poisoning, rather than flames, are the most common cause of death. This is about $70 \%$ of all fire deaths [12]. The cause of death in such situations is almost always improper operation of the facility in terms of fire safety, which leads to the inability to evacuate in a timely manner. Extreme conditions for evacuation, unpreparedness of people for a fire, ignorance of the evacuation plan, and often complex architectural and planning solutions of the building - all this negatively affects the time it takes to get out of the building when a fire risk occurs 
[13-16]. Thus, more than half of the smoke victims die on the spot. About $42 \%$ of the victims are severely poisoned, of whom one in three subsequently dies [12-17].

The above statistics show that the problem of evacuating people in a fire is extremely urgent and must be solved at the design stage of the building. It is possible to evaluate the effectiveness of architectural and planning solutions for evacuating a large number of people by calculating the individual fire risk. This article is devoted to the research of influence of architectural-planning decisions on fire risks in public buildings by calculation of an individual fire risk on the example of an office building and comparison of the received results.

\section{Methods}

As noted earlier, in addition to the extreme conditions during evacuation, the choice of the wrong architectural and planning solution can be a negative factor. For this experiment, two building layouts were used: corridor and mixed.

\subsection{Corridor planning scheme}

Typically, public buildings such as hospitals, schools, and offices use a corridor layout (Figure 1). In this layout, the main element is the corridor, from which all rooms on the floor, as well as the elevator (if any) and the stairwell, can be accessed. Rooms are located on both sides of the corridor, which maximizes the use of usable floor space [18-19]. However, this layout is considered the least efficient in terms of evacuation due to the narrow corridor and lack of sufficient natural lighting. In this case, when there is a lot of smoke, people in the building may have problems with orientation. Another significant problem with this layout is the possibility of blocking one of the evacuation exits.

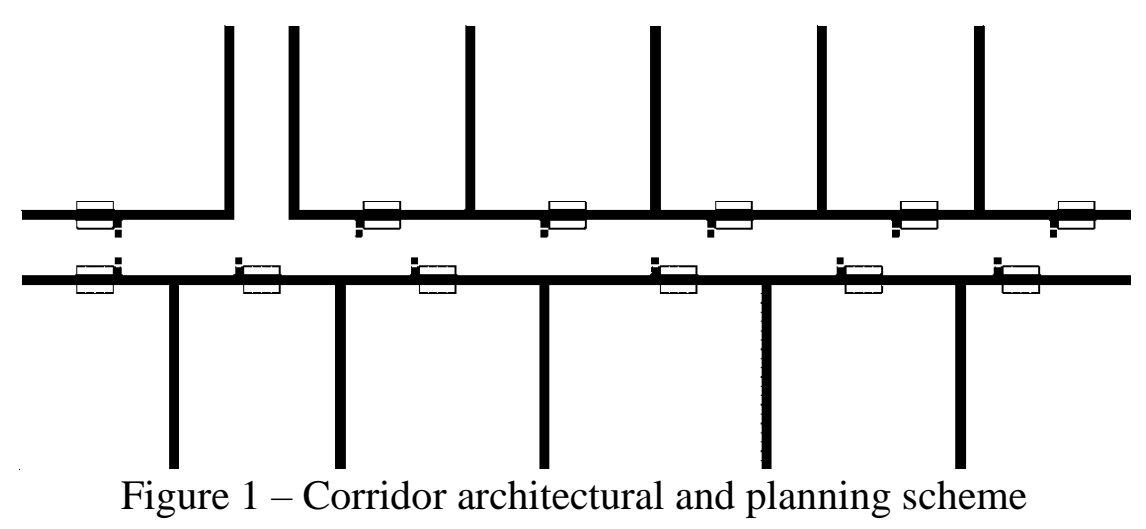

This type of layout and its subsequent calculation of individual risk are chosen as a reference point for comparison with an alternative architectural and planning scheme.

\subsection{Mixed-type architectural and planning scheme}

Theoretically, the proposed architectural and planning scheme of mixed type, which is based on the corridor layout scheme, could be an alternative solution.

It is assumed that such a layout scheme makes it possible to avoid the disadvantages of the corridor layout with a relatively small reduction in the space used on the floor. For example, in the gallery layout, which is a variation of the corridor layout, the proportion of usable space that can be used is significantly reduced because the rooms are located on one side of the corridor axis.

In the proposed scheme, the rooms will also be located on both sides of the corridor opposite each other, but a large central space is provided in the middle of that corridor, with staircases and elevators at both ends of that hall (Figure 2). The presence of a central space is a feature of the centric layout [20], so the proposed layout can be called a mixed-type layout. 

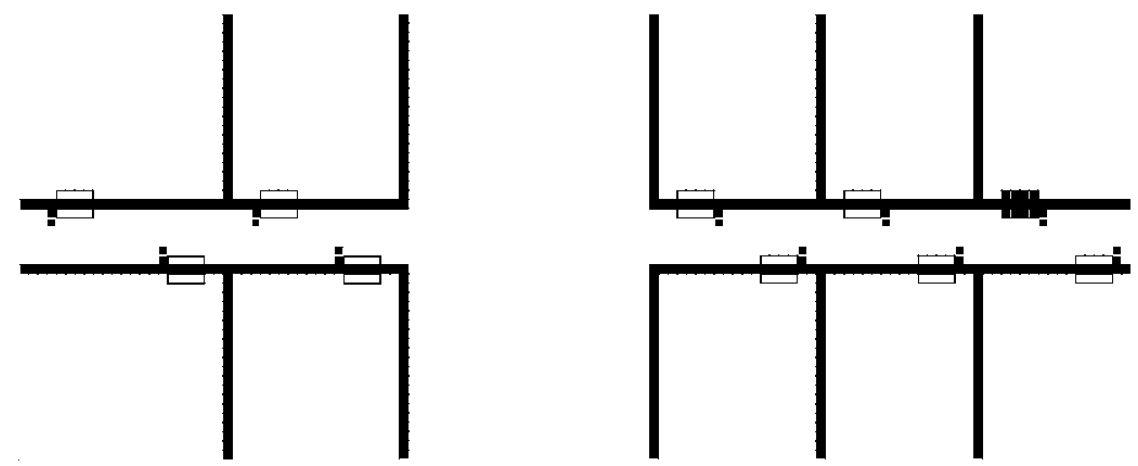

Figure 2 - Mixed-type architectural and planning scheme

Thus, in the case of evacuation, people will have the same access to the exits, which will be located in the central hall. Even if one of the evacuation exits is blocked, the distance to the other will be significantly less than in the case of the corridor layout. It is also assumed that the problem of lack of natural light in the corridors can be solved by the fact that windows can be installed in the central hall.

All of these factors indicate that a mixed-architecture layout can be effective from a fire safety standpoint and should be compared to the corridor layout type.

\subsection{Description of the calculation object}

The object for the calculation was a conditional office building with a free layout, located on the first floor of the building. These types of buildings are most often rented as open space, where the tenant has the right to choose their preferred layout of space. In this case, the total area of the space and the number of exits (two) remained unchanged (Figure 3). The width of each egress is one meter.

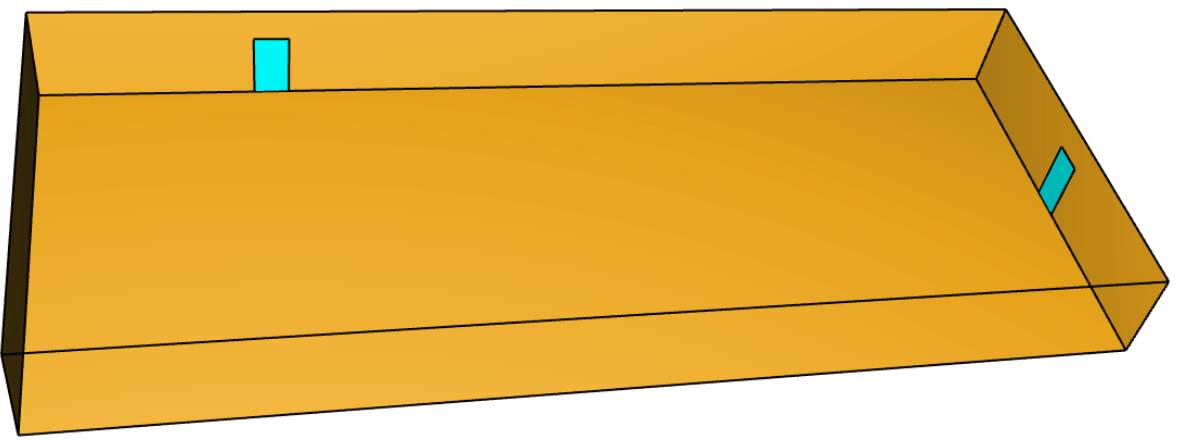

Figure 3 - General view of the room

General information about the building is shown in Table 1 below.

Table 1 - General information

\begin{tabular}{cc}
\hline Degree of fire resistance & II \\
\hline Number of floors & 5 \\
\hline Height of floors/premises & $3 \mathrm{~m}$ \\
\hline Distance to the nearest fire station & $2 \mathrm{~km}$ \\
\hline Facility operating time & $12 \mathrm{~h}$ \\
\hline
\end{tabular}

The building is equipped with a fire detection system, as well as a type 3 warning and evacuation control system. The building is not equipped with smoke ventilation system. There are no safety zones in the building. There is an automatic fire extinguishing system and it meets the regulatory requirements. There are people in the rooms at the rate of $6 \mathrm{~m}^{2} /$ person. The mobility group of all people in the building is healthy (mobility group M1). The building is not intended to be used by people with low mobility. 


\subsection{Description of calculation scenarios}

Scenario of fire was chosen according to Methodical Recommendations on Estimation of Individual Fire Risk of Public Buildings, approved by the Minutes of Session of Scientific and Technical Council of MES RK from October 26, 2011 № 12, and also on the basis of data on volumeplanning decisions, about the location of combustible load and people on the object. The calculation considers fire scenarios in which the worst-case conditions for the safety of people are realized. As scenarios with the worst fire conditions should be considered scenarios characterized by the most difficult conditions of evacuation of people and (or) the highest dynamics of growth of dangerous factors of fire (hereinafter - DFF).

In the case of a corridor-type layout, the fire occurs in the room near Exit 1 (Figure 4), the size of the fire source is $1 \cdot 2.5$ meters.

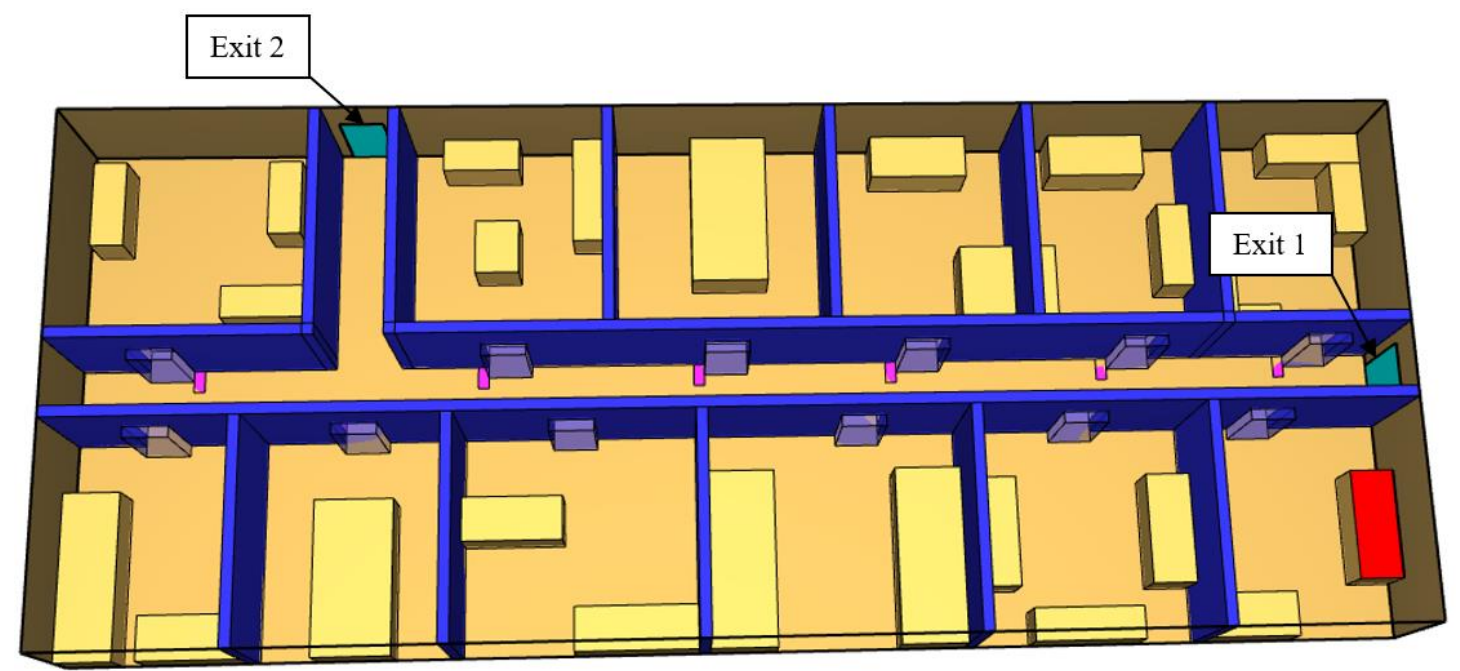

Figure 4 - Fire source emergence diagram for corridor planning scheme

The fire in the mixed scheme calculation occurs in the same area, but the location of the exits is different due to the use of the related of layout (Figure 5).

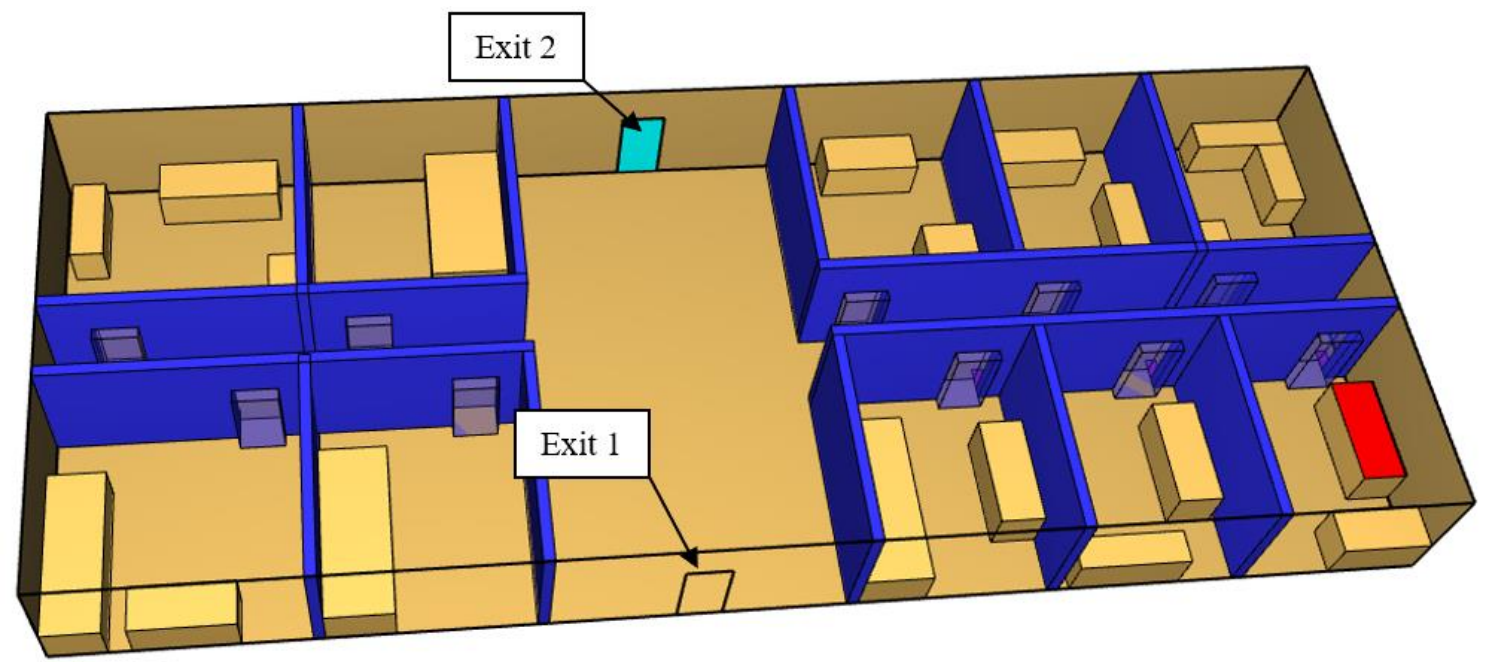

Figure 5 - Fire source emergence diagram for a mixed planning scheme

In both cases, when a fire occurs, smoke and other hazards enter the corridor and spread under the ceiling, forming a smoke layer, and descend, blocking the evacuation exits.

People from the fire room leave the room 6 seconds after the start of the fire and go to Exit 2, since the nearest Exit 1 is blocked by the fire hazards. People from other rooms start evacuating 90 seconds after the start of the fire, after receiving the signal of the alarm system, and move to Exit 2. 
Calculation of the fire scenario is performed in the software package FireCat, which includes the following programs:

- PyroSim program for calculating the spread of hazards in a fire;

- Pathfinder program for calculating the evacuation of people in a fire;

- FireRisk program to calculate the individual fire risk.

PyroSim program is a graphical interface for the program NIST: FDS 6, which implements a field model for calculating the propagation of DFF. This model is adopted for the calculation based on the following factors:

- The size of the fire source in the early stages of a fire is much smaller than the size of the room;

- Complex geometry of the object.

The Pathfinder program implements an individual-flow model for evacuating people. This model is adopted for calculation based on the following factors:

- People individually determine the path of travel;

- People flexibly choose which exit to evacuate through.

\section{Results and Discussion}

\subsection{Dissemination of hazards}

According to the results of fire hazard propagation calculations for the two layout models (Figure 6,7), there are no significant differences in $\mathrm{CO}_{2}$ emissions. This is not surprising, since the characteristics of the fire and its location remained identical. It is also worth noting that in the case of the corridor layout, the poisonous gas spreads further down the corridor, whereas in the mixed planning scheme, $\mathrm{CO}_{2}$ accumulation is observed mainly near the fire location.

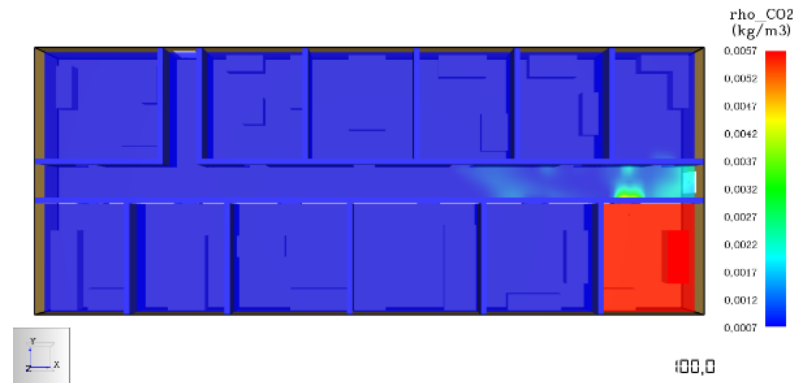

Figure $6-\mathrm{CO}_{2}$ propagation pattern in a corridor layout scheme

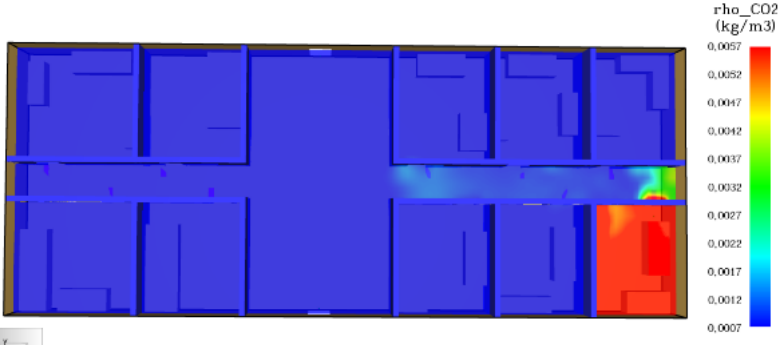

100,0

Figure $7-\mathrm{CO}_{2}$ propagation pattern in a mixed layout scheme

A similar pattern is observed in the distribution of heat across the floor. In both cases, the heat release rates are comparable (Figure 8, 9).

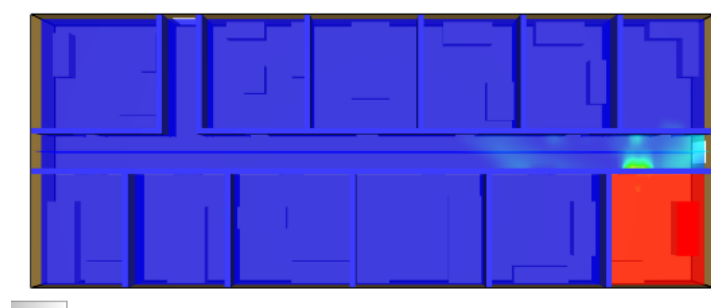

100,0

Figure 8 - Temperature propagation pattern in a corridor layout scheme

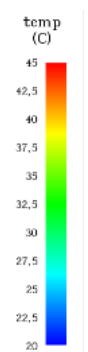

Figure 9 - Temperature propagation pattern in a mixed layout scheme 
As the results of calculations of the allocation of fire hazards show, specifically in this comparison of the two layouts there are no serious differences.

\subsection{Individual fire risk}

According to Methodical Recommendations on an estimation of individual fire risk of public buildings, confirmed by the report of session of Scientific and Technical Advice of MES RK from October, 26th, 2011 № 12, individual fire risk for an object of calculation should not exceed an admissible value $\left(1 \cdot 10^{-6}\right)$. Both calculation models do not exceed this value, and therefore the level of safety of people in case of fire meets the required one.

For the corridor layout, this figure was $0.75 \cdot 10^{-6}$, and for the mixed layout, it was $0.72 \cdot 10^{-6}$. The comparable figures indicate that the conditions of fire initiation and spread are similar. Theoretically, the results could be different if one of the models had a fire origin in a different location.

\subsection{Evacuation simulation}

Despite the similar results of the previous calculations, the main indicator of the effectiveness of the architectural and planning solution in this comparative analysis is the calculation of the evacuation of people (agents) on the floor.

Figure 10 shows a graph of the number of people remaining at each design point for the corridor layout - at the first moment in time, the graph shows the number of people that will pass through the design point during the simulation time, and at the following moments in time, the number of people not yet passed. At the moment when the number of people becomes zero, the evacuation through the design point is complete.

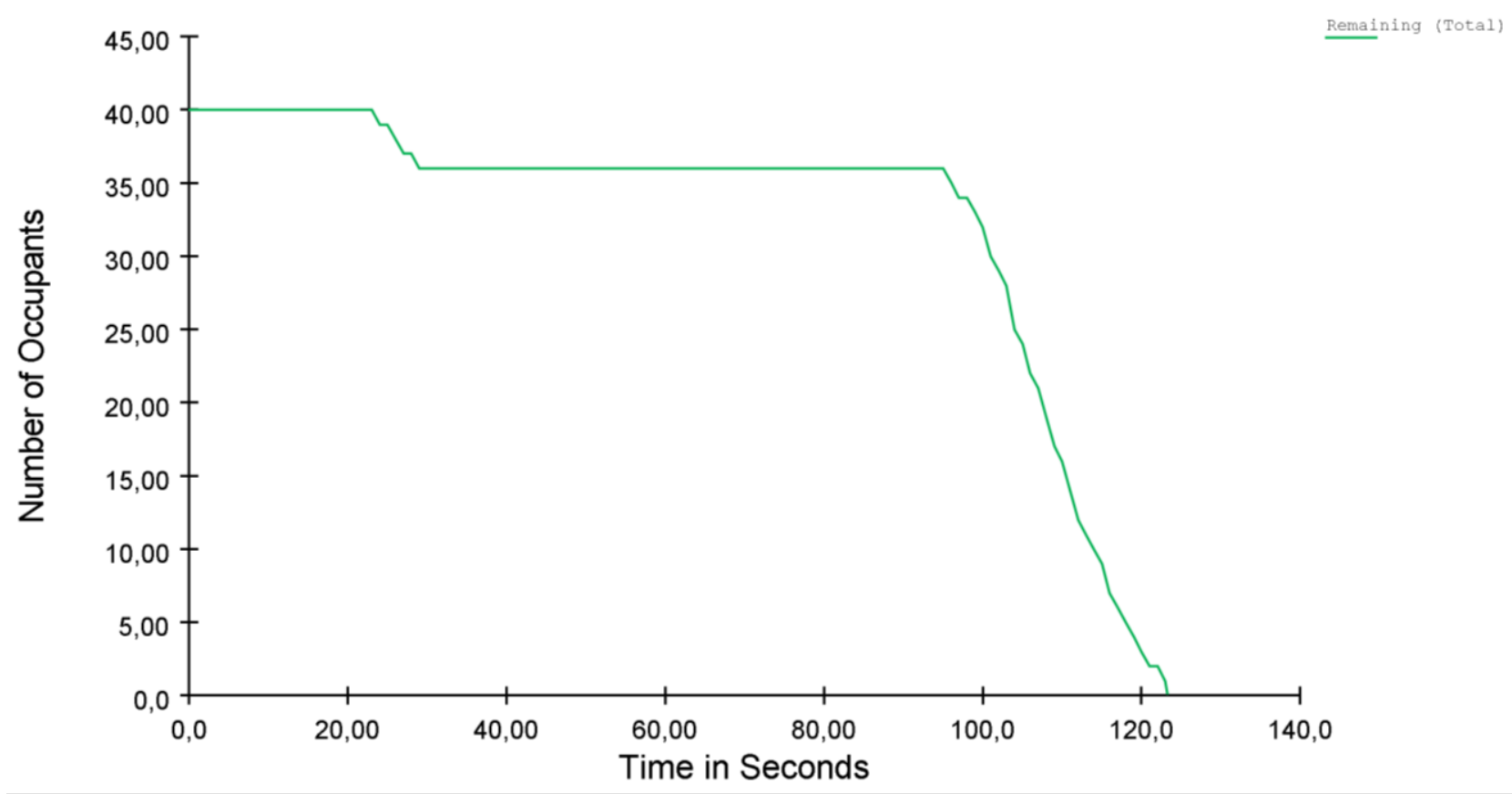

Figure 10 - Number of agents in selected rooms for the corridor layout

A total of 40 people participated in the evacuation, no non-evacuees. The total time taken for a complete evacuation was 123 seconds.

In the evacuation simulation case with the mixed plan layout, the results are noticeably better compared to the previous calculation. As in the first case, all 40 evacuees successfully left the building, but the evacuation time was 121 seconds, which can play a decisive role in a critical situation (Figure 11). 


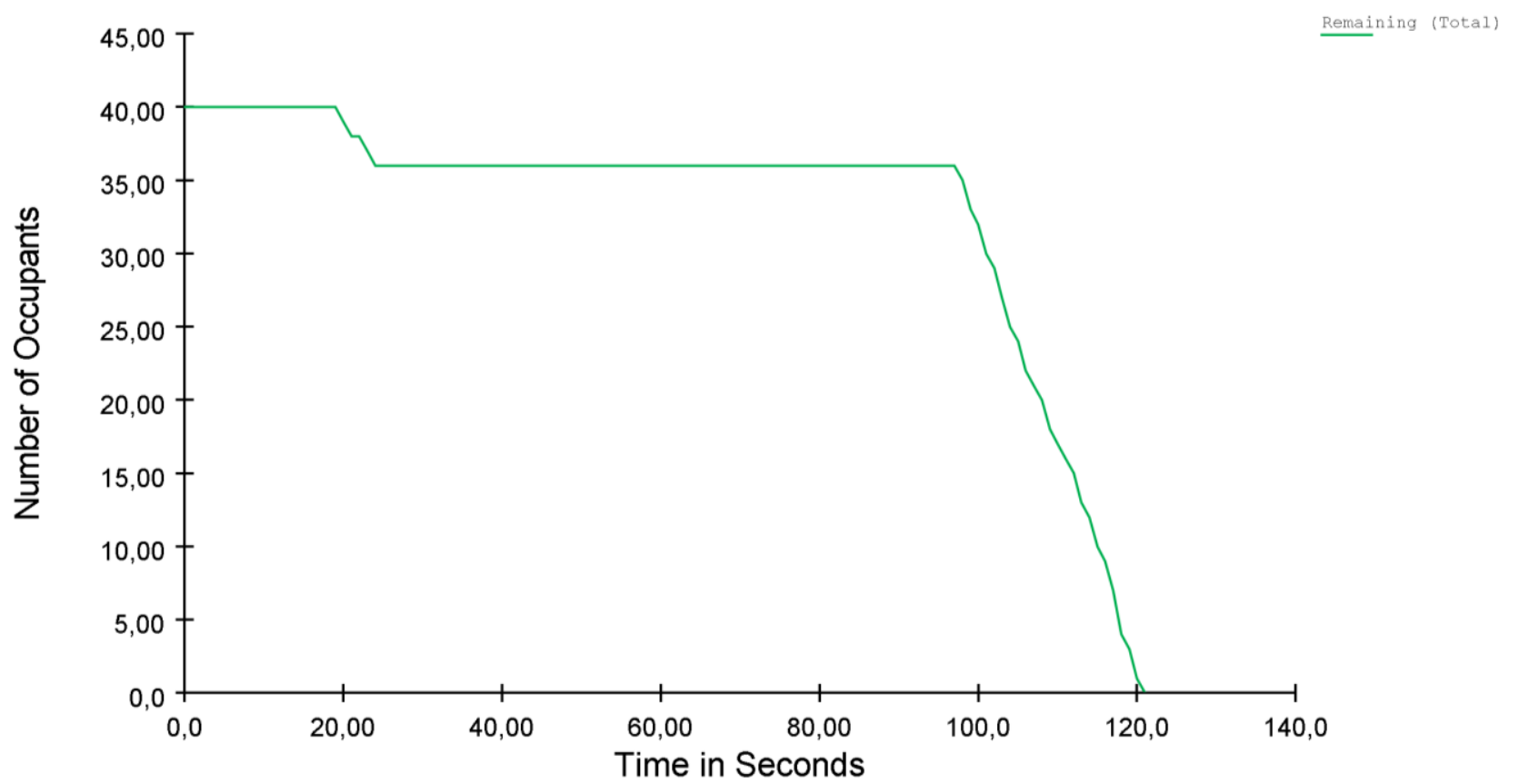

Figure 11 - Number of agents in selected rooms for the mixed-type architectural and planning scheme

During the simulation for the corridor layout, there was a large accumulation of agents in the corridor (Figure 12). This fact is due to the peculiarity of this type of layout. If one of the exits was blocked, agents would move from both sides of the corridor toward the nearest exit, which could cause difficulties for evacuation and crush. In the simulation it was avoided, but in practice it is likely that people evacuating will panic and the evacuation time will inevitably increase.

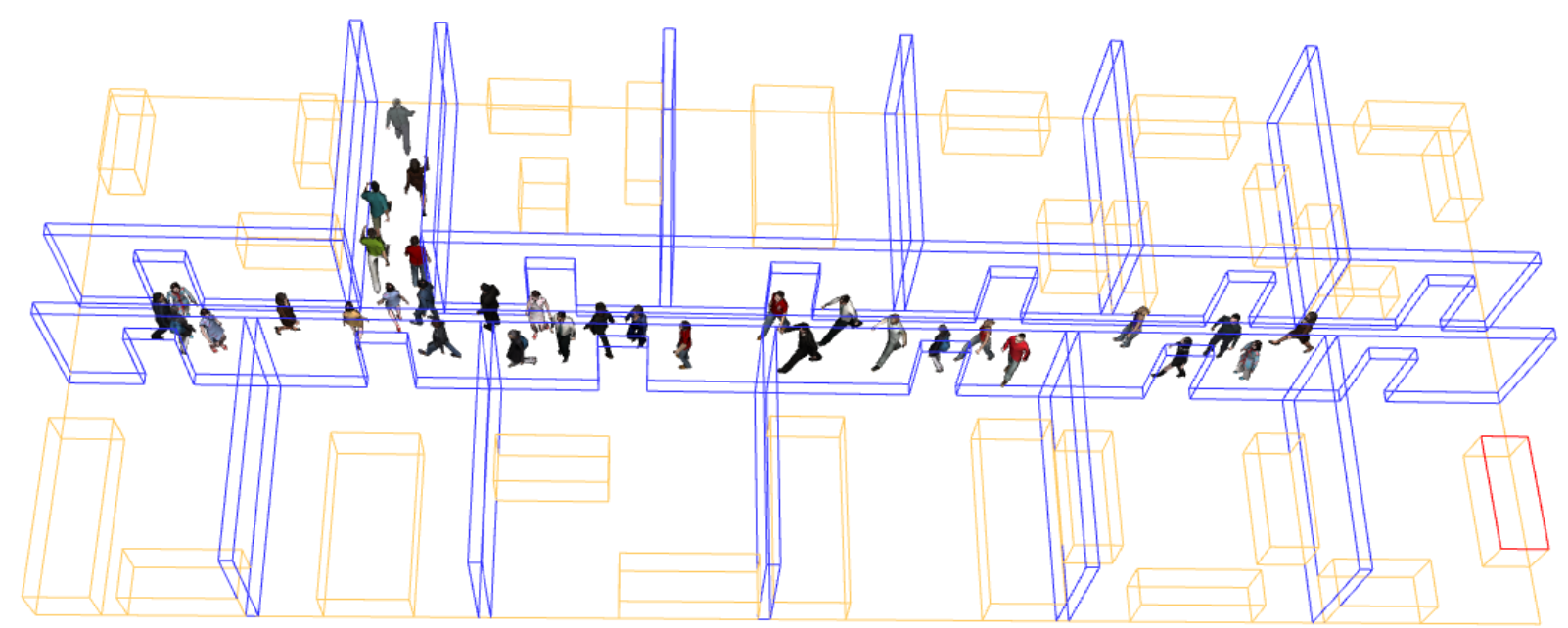

Figure 12 - Agent evacuation in corridor layout

In the agent evacuation simulation with the mixed layout there was no pandemonium, due to the presence of a central room (Figure 13). As in the first case, one of the exits was blocked, but it is more likely that panic will be avoided. The positive point is that the evacuation exits are located in the middle of the floor, which means that evacuation conditions will be equal for agents on both sides of the building. 


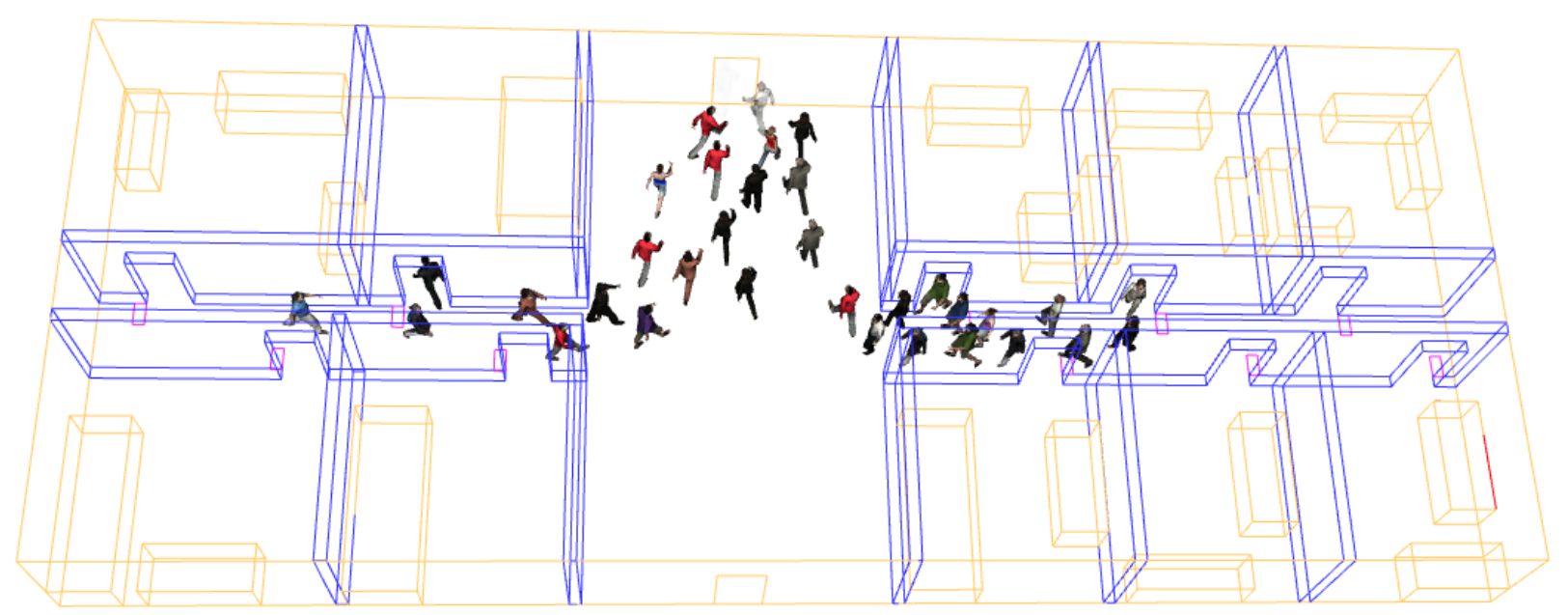

Figure 13 - Agent evacuation in a mixed layout scheme

\section{Conclusions}

In this article the influence of architectural and planning decisions on the fire risk of public buildings was investigated. On the example of an office building with a free layout were compared corridor and mixed layout schemes based on calculations in the software package FireCat. As a result, the following conclusions can be made:

1. The corridor layout makes the best use of the floor area of the building, but from a fire safety point of view, this solution is the least suitable;

2. The proposed mixed layout scheme has an insignificant loss of usable area at relatively high rates of fire safety;

3. The number of hazards in both cases is comparable due to the fact that the fire location and combustible materials are the same;

4. The individual risk score for the corridor layout type was $0.75-10-6$, and $0.72-10-6$ for the mixed layout type, indicating a preference for the latter.

5. In both cases, all agents were evacuated. The evacuation times for the corridor and mixed layouts were 123 and 121 seconds, respectively.

6 . The mixed layout solves the problem of pandemonium in the corridor by having a central hall on the floor.

\section{References}

1 On the commissioning of housing in the Republic of Kazakhstan. Agency for Strategic Planning and Reforms of the Republic of Kazakhstan Bureau of National Statistics, 2021.

2 ST RK 3020-2017 «Fire Safety. Assessment of fire risk. The method for determining the estimated values of fire risk in buildings and structures of various functional fire hazard classes», 2019.

3 Evaluation method for evacuation means use from high-rise building in fire case / A. Matveev, A. Maksimov, E. Kotkova // Contemporary Problems of Architecture and ConstructionCRC Press, 2021. — P. 433-438.

4 The solution of fire safety problems under a design stage with computer fire and evacuation simulation / E. Kirik, A. Dekterev, K. Litvintsev, A. Malyshev, E. Kharlamov // IOP Conference Series: Materials Science and Engineering: Vol. 456IOP Publishing, 2018. — P. 012073.

5 Modelling and finding optimal evacuation strategy for tall buildings / M. Aleksandrov, C. Cheng, A. Rajabifard, M. Kalantari // Safety science. — 2019. — Vol. 115. — P. 247-255. DOI: https://doi.org/10.1016/j.ssci.2019.02.017

6 Fire and evacuation in high residential buildings / R.B. Jevtic // Facta Universitatis, Series: Working and living environmental protection. - 2019. — P. 123-134. DOI: https://doi.org/10.22190/FUWLEP1802123J

7 Mechanism of fire risk management in projects of safe operation of place for assemblage of people [Text] / S. Yemelyanenko, A. Ivanusa, H. Klym // 2017 12th International Scientific and Technical Conference on Computer Sciences and Information Technologies (CSIT): Vol. 1IEEE, 2017. - P. 305-308. DOI: https://doi.org/10.1109/STC-CSIT.2017.8098792 
8 Fire risk assessment in dense urban areas using information fusion techniques / Z. Masoumi, J. van L Genderen, J. Maleki // ISPRS International Journal of Geo-Information. - 2019. - Vol. 8, № 12. - P. 579. DOI: https://doi.org/10.3390/ijgi8120579

9 The development of fire risk assessment method for heritage building / M. Ibrahim, K. Abdul-Hamid, M. Ibrahim, A. Mohd-Din, R.M. Yunus, M. Yahya // Procedia Engineering. — 2011. — Vol. 20. — P. 317-324. DOI: https://doi.org/10.1016/j.proeng.2011.11.172

10 Research on fire safety evacuation in a university library in Nanjing / M. Li, S. Zhu, J. Wang, Z. Zhou // Procedia engineering. — 2018. — Vol. 211. — P. 372-378. DOI: https://doi.org/10.1016/j.proeng.2017.12.025

11 Fire risk assessment for building operation and maintenance based on BIM technology / L. Wang, W. Li, W. Feng, R. Yang // Building and Environment. - 2021. - Vol. 205. - P. 108188. DOI: https://doi.org/10.1016/j.buildenv.2021.108188

12 Investigation of the effect of carbon monoxide on a person in case of fire in the building / D. Dubinin, V. Avetisyan, K. Ostapov, S. Shevchenko, S. Hovalenkov, D. Beliuchenko, A. Maksymov, O. Cherkashyn // Sigurnost. — 2020. — Vol. 62, № 4. - P. 347-357.

13 Agent-Based Modelling and Simulation for evacuation of people from a building in case of fire / S. Kasereka, N. Kasoro, K. Kyamakya, E.-F.D. Goufo, A.P. Chokki, M.V. Yengo // Procedia Computer Science. — 2018. — Vol. 130. — P. 10-17. DOI: https://doi.org/10.1016/j.procs.2018.04.006

14 Discovering worst fire scenarios in subway stations: A simulation approach / L. Zhang, X. Wu, M. Liu, W. Liu, B. Ashuri // Automation in Construction. - 2019. - Vol. 99. - P. 183-196. DOI: https://doi.org/10.1016/j.autcon.2018.12.007

15 Numerical investigation on fire accident and evacuation in a urban tunnel for different traffic conditions [Text] / A. Król, M. Król // Tunnelling and Underground Space Technology. — 2021. — Vol. 109. — P. 103751. DOI: https://doi.org/10.1016/j.tust.2020.103751

16 Epidemiological trends of severe burns, 2009-2019: A study in the service of burns in Albania [Text] / V.H. Filaj, M.K. Belba // Burns. — 2021. — Vol. 47, № 4. — P. 930-943. DOI: https://doi.org/10.1016/j.burns.2020.09.006

17 Learning from fire investigations and research-A Norwegian perspective on moving from a reactive to a proactive fire safety management [Text] / A. Steen-Hansen, K. Storesund, C. Sesseng // Fire Safety Journal. — 2021. — Vol. 120. — P. 103047. DOI: https://doi.org/10.1016/j.firesaf.2020.103047

18 Numerical investigation of airborne infection in naturally ventilated hospital wards with central-corridor type [Text] / Q. Zhou, H. Qian, L. Liu // Indoor and Built Environment. — 2018. — Vol. 27, № 1. — P. 59-69. DOI: https://doi.org/10.1177\%2F1420326X16667177

19 Crowdinside: automatic construction of indoor floorplans [Text] / M. Alzantot, M. Youssef // Proceedings of the 20th International Conference on Advances in Geographic Information Systems2012. — P. 99-108.

20 A review of occupant-centric building control strategies to reduce building energy use [Text] / S. Naylor, M. Gillott, T. Lau // Renewable and Sustainable Energy Reviews. - 2018. - Vol. 96. — P. 1-10. DOI: https://doi.org/10.1016/j.rser.2018.07.019

\section{Information about authors:}

Ulpan Auyezova - MSc Student, Department of Structural Engineering, L.N. Gumilyov Eurasian National University, Nur-Sultan, Kazakhstan, ulpan11.95@ gmail.com

Alizhan Kazkeyev - PhD Student, Department of Structural Engineering, L.N. Gumilyov Eurasian National University, Nur-Sultan, Kazakhstan, alizhan7sk@gmail.com 